\title{
Voluntary Mexican standard for sustainable building: environmental criteria and minimum requirements
}

\author{
M. Niño, A. Villa \& F. Tena \\ Direction of Urban Sustainability, \\ Ministry of Environment and Natural Resources, Mexico
}

\begin{abstract}
This paper presents the elaboration process and scope of the voluntary Mexican Standard for Sustainable Building (NMX-AA-164-SCFI-2013), headed by the Environment and Natural Resources Ministry. The NMX-AA-164-SCFI-2013 standard emerges from the Mexican government's need to have a regulatory instrument that impacts the current construction practices, leading them to a more sustainable model of edification, which contributes to the environmental protection, the integration of buildings within the city and its surroundings, the health and comfort of the building occupants and people's productivity. A multidisciplinary working group was jointed for drafting the document, comprising members of academy, industry, civil society and federal and local government. The starting point was the existing regulation and then setting higher levels of environmental performance and not only in the traditional schemes, such as energy efficiency and water use, but increasing its range by adding a new vision to the relationship between buildings and the city and with the environment, also the social responsibility and a life cycle approach. The Standard focuses on five different topics: Territory, Energy, Water, Materials and Waste, Environmental Quality and Social Responsibility. Each of these topics was established with mandatory and optional components. Once we have described the content of the Standard, we do a comparative analysis with other international certifications, especially with BREAM and LEED, looking for convergence points and the features given for the national context.

Keywords: sustainable buildings, standards, Mexico.
\end{abstract}




\section{Introduction}

Trends in design, materials and construction methods, as well as cultural practices and land use processes represent one of the main factors of pressure on natural resources and the global, regional and local environmental quality.

Recent studies on the costs of current urbanization highlight the need to reorient the current trends of land use looking for an efficient use of it, where the building can be a trigger for this process.

Certification schemes adopted in Mexico have shown the benefits and feasibility of this type of performance improvement practices, especially when they reinforce policies, strategies and national instruments: greater profitability for those who constructs, operates and maintains the building, comfort and health for those who live or use the building and reduction of impacts to the environment.

The challenge of the current federal environmental policy is to gradually change market from conventional buildings into green buildings, however:

- So far the issue of green building has focused on the direct impacts of energy efficiency and has abandoned other subjects like water efficiency, integrated solid waste management, risk prevention, the effects of the location (efficient use of urban land), connectivity and materials (efficient use of resources).

- The current sectorial approach to sustainable building focuses on several isolated aspects, making difficult to implement an integrated model where the different environmental factors of the building reinforce each other, according to the characteristics of each type of building and its geographical context. In this way, although sustainable use of energy is recognized as a core element of sustainability under this integrated approach, energy efficiency and renewable energy need to be attended synergistically with other building environmental and urban factors.

- From an environmental perspective, building location and design are crucial stages in order to reduce direct and indirect environmental impacts in a significant and permanently way. Therefore it's necessary to consider that energy savings in a green building will be achieved through efficient designs.

\subsection{Why a Mexican standard?}

Regulation is an appropriate means to facilitate market transparency and ensure the competence and suitability, guiding the acquisition of goods and services. However, in Mexico, construction process is often made breaking the mandatory standard, ignoring new technologies and products. Although most products for structures and facilities are regulated, constructors use uncertified materials.

A Mexican Standard on environmental issues is a self-regulation instrument set at the federal environmental legislation, voluntary for producers and companies in environmental improvement of their economic activities, assuming strict adherence to applicable laws and regulations and committing to meet or exceed high standards, goals or environmental benefits.

It can be used as a reference in regulatory programs, auto regulation, local environmental audits, for consumer protection and guidance regarding the 
determination of the quality of the building, and dispute resolutions in civil, commercial or administrative.

\subsection{Process and methodology for the development of the Mexican standard}

Standard elaboration was made in compliance with the Federal Law on Metrology and Standardization, regarding:

- Was registered in the Standardization National Program.

- International Standards were considered.

- Be based on the consensus of stakeholders involved in the committee and submitted to public consultation for a period of at least 60 calendar days prior to dispatch, by notice published in the Official Gazette. For compliance interagency working group composed of representatives from public, private and academic sectors and thematic subgroups organization to facilitate the development of the different sections of the rule was created.

The methodology for the development of the Mexican standard was based on the identification of the regulatory objectives, from which the requirements and technical specifications were developed for compliance. To ensure the implementation of an integrated approach an array was developed where, for each section of the standard, the minimum mandatory requirements were set and complemented with additional dispositions for more flexibility application.

Ordinary and extraordinary meetings were conducted and supported by a virtual forum for opinion exchange between working group members.

Public consultation had wide participation; around 1000 comments were received from different cities, professional sectors, expert builders, local governments, etc. improving the final content of the standard.

Review, update or cancellation of the standard shall comply with the same procedure followed for its establishment, but in all cases must be reviewed and updated within 5 years of the publication of the declaration of validity and should be reported to the Technical Secretariat results of the five-year review or update. If no notification is made, the cancellation order.

\section{Certification schemes}

\subsection{BREEAM}

BREEAM methodology has a percentage evaluation system with five different ratings, from PASS, with at least $30 \%$ of the credits, to OUTSTANDING with $85 \%$ of the credits or more. Mandatory credits have been set at all ratings, and these increases as the rating rises. You still need to gain the minimum percent for each rating band. (The analysis is based on BREEAM International New Construction Technical Manual SD5075-0.0:2013 version.)

The credits are grouped in technical sections with an associated weighting for each one. These weightings provide a means of defining, and therefore ranking, the relative impact of the sustainability issues covered in BREEAM. For the international version, the weightings are reviewed for the first project that registers 
for assessment in a country or region. These weightings are then set as appropriate for that project and all other projects thereafter in that country or region for the life of the current BREEAM International NC version.

\subsection{LEED}

LEED is point based rather than a percentage system, unlike BREEAM, with the basic certification, of 40 of 100 points, and 3 higher ratings being Platinum the highest with 80 points and above. (Analysis was made based on LEED 2009 for new construction and major renovations V3.0, issued by Spain Green Building Council.)

LEED has mandatory credits also, but unlike BREEAM, these prerequisites are mandatory for all ratings.

\subsection{Mexican standard. (NMX-AA-164-SCFI-2013)}

NMX-AA-164-SCFI-2013 is a voluntary standard issued by the Mexican national government and isn't linked to a certification, but provides minimal criteria and requirements to consider a building as sustainable, and brings basis to establish a Mexican certification in the future and create a mutual recognition agreement with existing certifications as BREEAM and/or LEED.

Like BREEAM and LEED, mandatory criteria has been set for NMX, and also contains some optional ones, however, as NMX not being a certification methodology, there is no score system.

It is worth mentioning that some of the criteria set in NMX aren't as detailed as in the international certifications analyzed in this paper, but often they are referred to several mandatory standards compliance, in which the procedures and requirements are well described.

\section{Comparison}

\subsection{Structure}

Requirements are grouped in specific technical sections in the three documents, with some coincidences in the chosen subjects, like Energy (Energy and Atmosphere in LEED's case) and Water (Water efficiency for LEED) which are the most common subjects in sustainable building requirements. Other common subjects are, for example, indoor environmental quality for both LEED and NMX and named Health and Wellbeing by BREEAM. Also, the characteristics of the land where the new construction is building are grouped in the subjects Land Use and Ecology (BREEAM), Sustainable Sites (LEED) and Land (NMX), but LEED and NMX includes transport and parking requirements in these sections, as only BREEAM has a Transport dedicated section. In the same way, NMX has a Biodiversity sub-section with the wildlife care measures, which some equivalence are included in "Land Use and Ecology" and "Sustainable Sites" sections. 


\subsection{Contents}

The structures show the intentions and emphasis of each scheme for certain topics; the Mexican standard, as being elaborated by the Mexican Ministry of Environment and Natural Resources, the organization is based in the environmental subjects related to buildings.

Energy is the main subject for both LEED and BREEAM, whereas Mexican standard remits to a specific mandatory standard issued by the Ministry of Energy. The great importance that American and British certifications give to the Energy may be related to high levels of energy consumption in northern countries, due to use of heating systems during winter and illumination at shorter days with lower amounts of solar light. On the other hand, temperature and daylight doesn't change much during all calendar seasons in most of Mexican territory due to its geographic location and conditions, so energy consumption by buildings is less in proportion to higher latitudes countries, as showed in the following table:

Table 1: Percent construction requirements.

\begin{tabular}{|l|c|c|}
\hline & United States & Mexico \\
\hline$\%$ Of total energy consumption & 40 & 17 \\
\hline$\%$ Of total electricity consumption & 68 & 25 \\
\hline
\end{tabular}

Data taken from a report of the Commission for Environmental Cooperation

Nevertheless, even if there are some little differences in the subjects of BREEAM, LEED and the Mexican standard, there are quite similar, as can be seen in table 2.

The most relevant differences are that LEED and the Mexican standard emphasises aspects of the site, while BREEAM has a detailed treatment of the management and aftercare.

On the other hand, it's worth mentioning that the issue of transportation is very homogeneous in the three schemes.

Another relevant coincidence is the importance given to monitoring energy consumption.

\subsubsection{Commissioning}

BREEAM and LEED both promote the commissioning, while there is no mention to this subject on the Mexican standard. This is because at this moment, we want to encourage the sustainable building as an extended practice, and the idea of commissioning could be received as a disincentive. However there are some new standards, that are a sort of by-products of the Mexican standard, that are considering the commissioning. 
Table 2: Comparative of the subjects included.

\begin{tabular}{|c|c|c|c|}
\hline Subject & BREEAM & $\begin{array}{l}\text { Mexican } \\
\text { standard }\end{array}$ & LEED \\
\hline Project brief and design & $\mathbf{X}$ & $\mathbf{X}$ & $\mathbf{X}$ \\
\hline Construction and handover & $\mathbf{X}$ & & \\
\hline Aftercare & $\mathbf{X}$ & & $\mathbf{X}$ \\
\hline Responsible construction practices & $\mathbf{X}$ & & $\mathbf{X}$ \\
\hline Construction site impacts & $\mathbf{X}$ & $\mathbf{X}$ & $\mathbf{X}$ \\
\hline Stakeholder consultation & $\mathbf{X}$ & & \\
\hline Inclusive and accessible design & $\mathbf{X}$ & $\mathbf{X}$ & \\
\hline Building user information & $\mathbf{X}$ & $\mathbf{X}$ & $\mathbf{X}$ \\
\hline $\begin{array}{l}\text { Post occupancy evaluation and } \\
\text { information dissemination }\end{array}$ & $\mathbf{X}$ & $\mathbf{X}$ & $\mathbf{X}$ \\
\hline Life cycle costing & $\mathbf{X}$ & $\mathbf{X}$ & $\mathbf{X}$ \\
\hline Daylighting & $\mathbf{X}$ & $\mathbf{X}$ & $\mathbf{X}$ \\
\hline Lighting & $\mathbf{X}$ & $\mathbf{X}$ & $\mathbf{X}$ \\
\hline Reduction of night time light pollution & $\mathbf{X}$ & $\mathbf{X}$ & $\mathbf{X}$ \\
\hline Indoor air quality & $\mathbf{X}$ & $\mathbf{X}$ & $\mathbf{X}$ \\
\hline Thermal comfort & $\mathbf{X}$ & $\mathbf{X}$ & $\mathbf{X}$ \\
\hline Minimising risk of water systems & $\mathbf{X}$ & $\mathbf{X}$ & \\
\hline Provision of fresh drinking water & $\mathbf{X}$ & & \\
\hline Acoustic performance & $\mathbf{X}$ & $\mathbf{X}$ & \\
\hline Noise attenuation & $\mathbf{X}$ & $\mathbf{X}$ & \\
\hline Pedestrian access & $\mathbf{X}$ & $\mathbf{X}$ & $\mathbf{X}$ \\
\hline Hazards prevention & $\mathbf{X}$ & $\mathbf{X}$ & \\
\hline Private space & $\mathbf{X}$ & & \\
\hline Energy efficiency & $\mathbf{X}$ & $\mathbf{X}$ & $\mathbf{X}$ \\
\hline Energy monitoring & $\mathbf{X}$ & $\mathbf{X}$ & $\mathbf{X}$ \\
\hline External lighting & $\mathbf{X}$ & $\mathbf{X}$ & $\mathbf{X}$ \\
\hline Renewable energy & $\mathbf{X}$ & $\mathbf{X}$ & $\mathbf{X}$ \\
\hline Energy efficiency: cooling & $\mathbf{X}$ & $\mathbf{X}$ & \\
\hline Energy efficiency: transportation & $\mathbf{X}$ & & \\
\hline Energy efficient equipment & $\mathbf{X}$ & $\mathbf{X}$ & $\mathbf{X}$ \\
\hline $\begin{array}{l}\text { Provide a low energy means of drying } \\
\text { clothes. }\end{array}$ & $\mathbf{X}$ & & \\
\hline Public transport accessibility & $\mathbf{X}$ & $\mathbf{X}$ & $\mathbf{X}$ \\
\hline Proximity to amenities & $\mathbf{X}$ & $\mathbf{X}$ & $\mathbf{X}$ \\
\hline Alternative modes of transport & $\mathbf{X}$ & $\mathbf{X}$ & $\mathbf{X}$ \\
\hline Maximum car parking capacity & $\mathbf{X}$ & $\mathbf{X}$ & $\mathbf{X}$ \\
\hline Travel plan & $\mathbf{X}$ & $\mathbf{X}$ & \\
\hline Allow home office & $\mathbf{X}$ & & \\
\hline Encourage mixed u & & $\mathbf{X}$ & $\underline{X}$ \\
\hline
\end{tabular}


Table 2: Continued.

\begin{tabular}{|l|c|c|c|}
\hline $\begin{array}{l}\text { Reduce the consumption of potable } \\
\text { water }\end{array}$ & $\mathbf{X}$ & $\mathbf{X}$ & $\mathbf{X}$ \\
\hline $\begin{array}{l}\text { Monitoring consumption of potable } \\
\text { water }\end{array}$ & $\mathbf{X}$ & $\mathbf{X}$ & \\
\hline Water leak detection and prevention & $\mathbf{X}$ & $\mathbf{X}$ & \\
\hline Water efficient equipment & $\mathbf{X}$ & $\mathbf{X}$ & $\mathbf{X}$ \\
\hline Used water treatment & & $\mathbf{X}$ & $\mathbf{X}$ \\
\hline Surface water run-off & $\mathbf{X}$ & $\mathbf{X}$ & $\mathbf{X}$ \\
\hline Responsible sourcing of materials & $\mathbf{X}$ & $\mathbf{X}$ & $\mathbf{X}$ \\
\hline Thermal insulation & $\mathbf{X}$ & $\mathbf{X}$ & $\mathbf{X}$ \\
\hline Reduction of Heat Island Effect & & $\mathbf{X}$ & $\mathbf{X}$ \\
\hline Designing for robustness & $\mathbf{X}$ & & \\
\hline Construction waste management & $\mathbf{X}$ & $\mathbf{X}$ & $\mathbf{X}$ \\
\hline Reduce pollution from materials & $\mathbf{X}$ & $\mathbf{X}$ & $\mathbf{X}$ \\
\hline Management of operational waste & $\mathbf{X}$ & $\mathbf{X}$ & $\mathbf{X}$ \\
\hline Contaminated land remediation & $\mathbf{X}$ & $\mathbf{X}$ & $\mathbf{X}$ \\
\hline Materials efficiency & $\mathbf{X}$ & $\mathbf{X}$ & $\mathbf{X}$ \\
\hline Protect ecological site's value & $\mathbf{X}$ & $\mathbf{X}$ & $\mathbf{X}$ \\
\hline Enhancing site ecology & $\mathbf{X}$ & $\mathbf{X}$ & $\mathbf{X}$ \\
\hline $\begin{array}{l}\text { Minimise long term impact on } \\
\text { biodiversity }\end{array}$ & $\mathbf{X}$ & $\mathbf{X}$ & $\mathbf{X}$ \\
\hline Landscape & $\mathbf{X}$ & $\mathbf{X}$ & $\mathbf{X}$ \\
\hline Green roofs & & $\mathbf{X}$ & \\
\hline Reduce building footprint & & \\
\hline Include amenities for workers & & \\
\hline
\end{tabular}

$\mathbf{X}$ means the subject is present on the scheme.

Gray hatch means it is mandatory.

\subsubsection{Waste}

BREEAM scheme has different sections for Materials and Waste, while Mexican standard group both subjects with the purpose of strengthening the link between them; an efficient use of materials reduces the amount of waste, while some waste could be reused as construction materials. It's worth mentioning that LEED doesn't have a specific Waste section, but the credits related to this subject are contained in Materials and Resources.

Mexican standard establishes as mandatory the accurate management of construction waste according the local and national legislation in the matter. In this way, the mandatory standard NOM-161-SEMARNAT-2011 sets the obligation to generators of waste from building construction, maintenance and demolition activities, of submit a Management Plan, where generation reduction, reuse, recycle and proper disposal strategies have to be set. With this framework, the Ministry of Environment and Natural Resources, signed a cooperation agreement with the Mexican Chamber of Construction Industry (CMIC), to elaborate the Construction and Demolition Waste Management Plan, which aims 
to contribute to the sustainable building, minimizing the generation of waste from construction and demolition and maximizing its reuse, in a shared responsibility concept between the three levels of government and different actors in the construction industry value chain.

BREEAM and LEED establish more detailed requirements in the dedicated space for waste storage and higher levels of recycled materials in the construction process than the Mexican standard, but in the other hand, Mexican standard sets goal for generation reduction in the operational waste $(20 \%$ less than the previous year) and BREEAM and LEED focus more in recycling.

\subsubsection{Materials}

The three schemes consider the use of recycled materials, but there are different approaches, while BREEAM specifies the use of an amount of at least $25 \%$ of recycled aggregates, the Mexican standard is less accurate, because doesn't detail what kind of materials are suitable to use recycled matter.

Both BREEAM and the Mexican standard encourages a Life Cycle Approach in the selection of materials, but BREEAM unlike the Mexican standard has developed a tool to calculate it.

\section{Conclusions}

Since the first certification schemes of sustainable buildings there has been a homogenization of subjects. However still remaining subtle differences; such as the standards, the base lines, or the ranking of priorities.

Some distinctions are due to cultural differences, for example the point "provide a low energy means of drying clothes" because in Mexico the most usual is to dry clothes lying to the sun. But some other are due to the experience gained through the years, so that, the incoming Mexican standard could be reinforced by the international experience.

After this comparison we have concluded that it is possible, and even desirable to use the existing certifications as a way to accomplish with the Mexican standard.

We also concluded that all the certification schemes could work coordinated and that they could be used as inputs. During the process of elaboration of the Mexican standard, it was largely discussed the need of a base line, that's why it is mandatory to report the energy and water consumptions. Given that LEED and BREEAM schemes also includes the energy report, a world wide data base could be done with such information, that allows us all to know how the certifications have been modifying the building practice, so we can move even forward, with increasingly higher standards.

\section{References}

[1] Commission for Environmental Cooperation, Edificación Sustentable en América del Norte, CEC, Bibliothèque nationale du Canada, p. 22, 2008.

[2] BRE, BREEAM International New Construction Technical Manual, SD50750.0:2013, BRE Global Ltd., 2013. 
[3] US Green Building Council, LEED 2009 para nueva construcción y grandes remodelaciones, Versión 3.0, Spain Green Building Council, 2009.

[4] Starrs, M. \& Burrows, V.K., BREEAM versus LEED, Inbuilt Ltd, UK, pp. 513, 2010.

[5] Cámara Mexicana de la Industria de la Construcción, Plan de manejo de residuos de la construcción y la demolición, CMIC, México, p. 5, 2013. 